\title{
A STORY OF SOUTH-EAST ASIAN TESOL WHY TEACH ABROAD: ITS OPPORTUNITIES AND CHALLENGES
}

\author{
${ }^{\mathbf{1}}$ Luthfi Nicola Sereni \& ${ }^{2}$ Elih Sutisna Yanto \\ ${ }^{1}$ Pre-Service English Teacher, FKIP, Universitas Singaperbangsa Karawang, Indonesia \\ ${ }^{2}$ English Education Lecturer, FKIP, Universitas Singaperbangsa Karawang, Indonesia Co. \\ Corresponding Author Email: luthfinstkj@gmail.com
}

\begin{tabular}{ll}
\hline \hline Article Info & Abstract \\
\hline Article History & This study aimed to investigate a story from a South-East Asian TESOL teacher. \\
Received: June 2021 & The purpose of this study is to inspire and guide in-service and pre-service \\
Revised: July 2021 & English teachers to teach EFLESL overseas either to native English-speaking or \\
Published: July 2021 & non-native English-speaking countries. The participant of the study is a BA \\
\hline Keywords & TESOL Teacher from the Philippines teaching English in the Kingdom Saudi of \\
EFL Teachers; & Arabia. The data were collected through a semi-structured interview and \\
Native English Teachers; $;$ & analyzed through Braun \& Clarke's thematic analysis. The data then will be \\
Non-Native English & coded, read multiple times, and themes were assigned and generated. The \\
Teachers; & findings describe that teaching abroad provides better prosperity and additive \\
Teaching EFL/ESL & $\begin{array}{l}\text { and transformative development for the teachers. However, teachers that aim to } \\
\text { Abroad; }\end{array}$ \\
& teach abroad should be globally accepted and possess proper identity and agency \\
& to overcome culture shock, language differences, homesickness as the common \\
& challenges of teaching abroad. Overall, teaching abroad should be considered \\
& greatly by teachers who are interested in receiving a higher salary and involved \\
various teachers'development experience.
\end{tabular}

How to cite: Sereni, L. N., \& Yanto, E. S. (2021). A story of South-East Asian TESOL why teach abroad: Its opportunities and challenges, JOLLT Journal of Languages and Language Teaching, 9(3) DOI: https://doi.org/10.33394/jollt.v\%vi\%i.3978

\section{INTRODUCTION}

Globalization has transformed the role of the English language to be incorporated globally as an international language or medium instruction. People globally incorporate English to pursue a better career, education, or transferring technology from one country to another. Most bona fide higher education institutions already incorporated English as a medium of instruction (EMI) while multinational or international companies require English as an obligatory requirement for their employee candidates (Alhassan, 2019). Thus, English is in high demand nowadays due to globalization (Graddol, 2000). Moreover, this phenomenon has increased the demand for English teachers globally. At first, most non-native English countries (NNECs) preferred to hire native English teachers (NETs), then sending non-native English teachers (NNETs) to enroll in TESOL majors in higher education (Kong, 2016). Yet the demand seems to increase over time as there are various NNEC who also hire foreign NNETs to teach English in their countries as reported in ASEAN (Ulla, 2019 Frederiksen, 2014) and Hongkong (Benson, 2012).

The increasing demand for English teachers always leads to a similar discussion regarding which one is better NETS or NNETs in terms of teaching English to speakers of other languages., The discussion often explores the strength and weaknesses of NETs and NNETs. NETs are always assumed to possess superior linguistic competence while NNETs are richer in the learning experience as they learned grammar, vocabulary, and macro skills of other languages that could be transpired among learners (Shin, 2008). Nevertheless, older literature agreed that the discussion in terms of the strengths and weaknesses of NETs and NNETs should 
not be explored as they simply do not exist as both have their strength and weaknesses. NETs may be superior in linguistic competence, yet do they possess the pedagogical skills that are needed? While NNETs may be superior in the learning experience that affects their pedagogical skills. However, learners frequently need to be exposed to native speakers of English either through face-to-face interaction or any other interaction (Rampton, 1990). This is just one of the examples of why discussing the strength and weaknesses between NETs and NNETs is a pointless discussion; overall it is impossible to determine whether one is superior to the other. (Davies, 1991). As the discussion only leads to subjective marginalization which often discredits NNETs as hiring English teachers based on their nationality leads to a caste system among English teachers, higher compensation for NETs, and higher employability for NETs. (Kachru, and Nelson, 1996; Amin, 2004). However, despite the pointless debate, few studies have discussed and elaborated on the reasons why the demand for NNETs increases overseas. NETs possess what NETs do not have, as NETs regard English as their mother language, NNETs regard English as a foreign language they must make sense of English grammar to their mother language. This mostly leads them to discover learning strategies and developing a teaching strategy based on their learning experience. Their struggles when learning the language can also be shared among learners as a reflection during learning. Henceforth, NNETs are often determined to be good role-model for language learners (Medyges, 1994).

Previous studies have explored the stories of Filipinos and Chinese EFL teachers These explored their successes and challenges of being NNETs who teach overseas. Ulla (2019) and Frederiksen (2014) reported that most of the Filipinos participating in her study received a better salary than in their home country and this factor is mostly the main factor why Filipino English teachers teach overseas. Teaching overseas not only be able to deliver better prosperity, but it also offers professional development as most of the experts in TESOL had been teaching overseas. Moreover, NNETs who teach overseas usually develop their professional career through enrolling in higher education in TESOL e.g MA TESOL or professional certifications (Kong, 2016; Clark \& Paran, 2007). However, the issue of the marginalized view of NNETS still exists as some learners prefer NETs to NNETs, and NETs receives a higher salary than NNETs, and in terms of employability., NETs still has a higher chance to be employed than NNETs (Ulla, 2019; Benson, 2012).

This study does not discuss the strength and weaknesses between NETs and NNETs as the issue is often discussed as both have their strength. NETS possesses superior linguistic skills while NNETs provide a richer learning experience. However, both of them could be competent teachers with proper content and pedagogical knowledge. The stories of NNETs teaching overseas discussing their challenges and successes are still underexplored (Benson, 2012). A study conducted by Benson (2012) reported the issues of Shanghainese teachers who teach abroad in Hongkong. They shared identical mother language with the students, however, they struggled to connect to the world of their students. While Ulla (2019) and Frederiksen (2014) reported Filipino English teachers who teach in Bangkok, Thailand, they reported the teachers' experience, perceptions, and motivation on teaching abroad Thus, this study is based on the authors' empiricism on Pre-Service English teachers who abandon to be English teachers and prefer to work in another field to receive a proper salary. Therefore, this study aims to provide detailed insight and procedure for Pre-Service English teachers regarding teaching abroad as previous studies mostly covered their teaching experience rather than providing more detail on how they teach abroad and explore teacher's identity and agency that occurs in the story especially for those who reside in countries that have a low rate of salary for teachers through excavating detailed and valuable information based on teaching stories and experiences of an NNETs (Ulla, 2019; Frederiksen 2014; Benson, 2012). This study also aims to emphasize that BA TESOL graduates would be able to fulfill the expectation to teach language to speakers of other languages through lensing a story of an NNET who already teaches overseas and discover 
its similarities and distinctions to provide new insight regarding NNETs teaching overseas. Hence, the study proposed to investigate What are the preparations, challenges, and opportunities of NNETs in teaching overseas?

\section{LITERATURE REVIEW}

\section{Native English Teachers and Non-Native English Teachers}

NNETs who teach overseas must be prepared to address issues related to the classroom. They teach in an unfamiliar environment, mostly in public or private schools that incorporate English as a Medium of Instructions (EMI). However, despite the schools incorporate EMI, students often do not communicate in English for daily conversation. As a result, teachers often struggle to communicate with students from other countries. These challenges students to improve their language proficiency level. Furthermore, NNETs must possess a high level of language proficiency and exposure to compete NETs. (Moussu and Lurda, 2008). Despite the challenges, NNETs possess strengths compared with NETs who often do not possess them. In essence, NNETs have experience of learning a foreign or second language (Medyges, 1994); they struggle and understand the challenges of learning a foreign or second language. In essence, NNETs have experience of learning a foreign or second language; they struggle and understand the challenges of learning a foreign or second language. This will assist the NNETs in predicting and overcome challenges in teaching English. Árva \& Medgyes, (2000) and Barratt \& Kontra (2000) suggesting that through experiences of learning a foreign or second language, NNETs can be more emphatical to the learners as they shared similar learning experience with their students.

However, despite the strengths of NNETs, the marginalized view regarding NNETs still exists and affects their employability. For example, NETs are often reported to possess superior linguistic competence rather than NNETs do, and NETs are often preferred as they offer an authentic experience in learning English. (Shin, 2008) This often leads NETs to receive a higher salary and compensation rather than NNETs (Ulla, 2019; Frederiksen, 2014; Benson, 2012). This affects a higher rate of employability for NETs than NNETs., Even some schools prefer to hire NETs than NNETs without considering their teaching competence (Clark \& Paran, 2007). Moreover, the NETs often are more preferred by learners than NNETs (Ulla, 2019; Frederiksen, 2014; Benson, 2012).

\section{Determining Who to Hire NETS or NNETS, Nationality, or Competence?}

Although competence of teaching and pedagogy affect the effectiveness and success of learning English for language learners, many educational institutions or schools prefer to hire NETs than NNETs. (Merino, 1997). The discussion of who is better often leads to a pointless discussion as both NNETs and NETs could be competent teachers depending on their linguistic and pedagogical competence. Both NETs and NNETs may be struggling to teach unfamiliar topics. NETs may be superior in terms of linguistic competence, yet NNETs possess rich learning experience and even may incorporate students' mother tongue to communicate with them (Medyges, 1992).

Therefore, employers who are willing to hire an EFL/ESL teacher should avoid considering criteria that are no relevant to EFL/ESL teaching., For example, language background, ethnicity, citizenship, educational level, and socioeconomic status. Employers should consider what the teachers have for their professional development, years of experience in teaching EFL/ESL, qualifications, and their pedagogical and linguistics skills that can be selected through micro teachings and language proficiency tests for non-native teachers. (Merino, 1997; Medyges, 1992). Despite this recommendation, schools and educational institutions prefer to hire white NETs (see Ulla, 2019; Frederiksen, 2014; Kong, 2016; Kubota \& Lin, 2006). 


\section{Stories of NNETS Teaching Overseas}

A study conducted by Benson (2012) reported the stories of 2 NNET female pre-service teachers who studied and teach in Hong Kong. The language repertoire of the teachers is Shanghainese as the mother language and Putonghua as the second language. They learned and acquired English in China their homeland country. They were granted a scholarship that offered them the opportunity to study and teach TESOL in Hong Kong. It was a tremendous opportunity for them as they expected that a country that employs ESL would offer them a higher exposure to English and the new environment would be suitable for their career development. A similar study conducted by Ulla (2019) and Frederiksen (2014) reported the experience of Filipino English teachers who teach in Thailand. Despite that, both the Philippines and Thailand are geographically located in the same region, yet these Filipino teachers decided to pursue their careers in Thailand. Ulla (2019) and Frederiksen (2014) described that this case has existed Thailand offers better prosperity and also employs non-local NNETs as Thailand Government perceives that by hiring NETs and non-local NNETs, the English proficiency index in their country would be progressively increased. Moreover, the Filipino teachers understand that in their country, as in other developing countries, teachers are still underpaid and it is better to teach in other countries that pay well. Also, teaching in Thailand provides new insight into teaching as the teachers must adapt to different cultures and working environments starting from their co-workers, supervisors, and their students. A rich multicultural experience will be beneficial for their teaching career and this is also supported by the fact that most experts in TESOL are also experienced in teaching in other cultures.

Despite the previous studies have reported the stories of NNETs in teaching overseas, yet these studies do not provide detailed information regarding the procedure of NNETs applying for a teaching career overseas or excavating transformation or development of the teachers' agency and identity, the authors experienced that most pre-service English teachers that he encountered perceived that they can only teach in their home country or apply for another general undergraduate career. Therefore, this study will provide detailed information regarding the hiring procedure by lensing experiences between an NNET who already teaches abroad. The study aims to be an inspirational reading and guidance for pre-service English teachers and English teachers in general that they can enhance their teaching career and prosperity by teaching overseas while providing detailed information on the hiring process.

\section{RESEARCH METHOD Research Design}

This study aims to provide insight for TESOL/TEFL teachers and Pre-Service English Teachers through discovering hidden valuable information that resides in the story of Rodriguez when he teaches English abroad. Thus, this study employs a narrative inquiry particularly a biography research design as this study aims to transform a story into inspirational and valuable information as a guide for its readers (Creswell et al, 2011). Additionally, A narrative inquiry design is used to explore one's lived experience (Clandinin \&Connely,2000; Clandinin \& Rosiek,2007). This design allows the authors to re-tell the participant's experience in teaching English abroad.

\section{Subject and Context}

There is no research site in terms of place or location as this study focuses on the teachers' experience on teaching abroad and preparation for it. Also, this study does not aim to generalize its results. Instead, this study only provides inspirational and valuable information for those who want to teach English abroad. The study involved one participant of Filipino TESOL teachers who has been teaching English overseas. A narrative inquiry mostly recruits just one or two individuals (Creswell, Klassen, Plano, \& Smith, 2011). The authors met with the Filipino teacher on Arizona State University TESOL Facebook Group and exchanged 
discussions regarding TESOL through online platforms numerous times. The authors then contacted him through email, offered him the opportunity to participate in the study. The authors have delivered a consent form that the Filipino teacher already signed. Thus, the Filipino teacher expressed in spoken and written form that voluntarily participated in this study.

The authors involved Rodriguez as a pseudonym name for the Filipino teacher. He is a 31-years-old male TESOL teacher. He has a bachelor's degree in English for Secondary Education and has been teaching for more than 10 years. He is currently studying for a Master of Educational Management Study. He is also a certified TESOL teacher and earned his Professional License for Teachers in the Philippines. His linguistic repertoire includes Filipino or Yloco as his mother tongue., His proficiency in English is advanced level as proven by his C1 CEFR and 7.0 IELTS score. He is currently teaching in a corporate technical training center in the Kingdom of Saudi Arabia.

\section{Instruments}

In this study, the authors use a semi-structured interview and follow-up emails to collect the data. Furthermore, this study employs a deductive way of analyzing the data that were investigated by the participant. The deductive themes covered the experience of the Filipino Teacher in teaching English abroad. Following (Ulla, 2019; Frederiksen, 2014; Benson, 2012) through the story, the themes were coded, juxtaposed, and analyzed.

The Filipino teacher, Rodriguez firstly approached by the authors by contacting him through a chat messenger application. The authors asked about his availability and willingness to participate in this study. The authors also described the aim of this study to him. After he agreed to participate in this study, the authors delivered a consent form for him to sign. Then he signed the form legalizing his participation in this study. Furthermore, the authors gathered his demographic information collected through follow-up emails. The authors then designed the following deductive themes (1) Prior Teaching Abroad (2) Preparations to Teach Abroad (3) Challenges and Opportunities of Teaching Abroad (4) Teacher's Reflection. Then, the authors and Rodriguez scheduled and had an online meeting to share his story regarding teaching overseas. Rodriguez also agreed that the authors would send follow-up emails to gather further information.

\section{Data Analysis}

This study aims to gather a story and investigate valuable information that lies in the story. The story then is regarded as a reflection for other pre-service English and in-service teachers. Thus, the authors employed Braun \& Clarke's thematic analysis to explore and analyze the hidden valuable information which risen throughout the story. The interview transcription was re-read multiple times and extensively. The interview scripts were coded and grouped according to the research questions to discover the valuable information to answer the research questions (Braun \& Clarke, 2012). The data were investigated through exploring the story of a Filipino teacher including his preparation for teaching overseas. The data then were coded to generate sub-themes. The sub-themes then were assigned to fit the deductive themes that have been assigned. Through this, the authors explored what should be considered and prepared in preparing to teach overseas. The results of the story then were lensed through a theoretical lens proposed by Ulla (2019) and Benson (2012).

\section{FINDINGS AND DISCUSSION Findings}

The findings will be presented under the four headings informed by the participant about his experience in teaching English overseas.

\section{Prior Teaching Abroad}

The $1^{\text {st }}$ deductive theme in this study discovered the participant's identity and agency before taking the job as a teacher. The participant was aware that he needed to take a major that 
was possible for him to finish on time. The participant was aware that English Secondary Education major was the easiest for him to finish. He had no interest to be a teacher before taking the major. However, his interest increased as he studied, graduated, and work as a teacher.

\section{Excerpt 1}

"I thought that English education was the easier for me to finish it. I like teaching, but it just grew on me because I didn't think to be a teacher. But I had the chance so it just grew on me.

Once the participant graduated from his bachelor's study, it was impossible for him to directly apply as a teacher in secondary schools as he graduated in the middle of the year. He needed to apply for a non-teaching job while waiting for another opportunity to apply as a teacher. However, before applying for a teaching job, teachers in the Philippines are required to have an official teaching license by the government.

Excerpt 2

"I graduated in the middle of the year, it was 2010 around October. Our Schools starts from June to March. So, in between, we have October as a semester break. After that, I worked as a secretary admission officer in a hospital because I could not teach yet officially because I did not yet have a license. We can't teach without the license. So, that is the basic requirement"

A few months later, the participant finally was accepted as a teacher in a private high school. When asked about the salary, he said that he receives $\$ 150$ a month as his first salary. He expected such a small salary and he felt that it would not be an issue for him as he was aware of the possibility and himself being a new teacher.

Excerpt 3

"I got around \$150. I was a new teacher and that was 2010 in a private school. It was a very small school, So I did not expect me to pay me much.

After a year of teaching in a private high school, the participant resigned from the job. He felt that the job was focused only on means of gaining optimal results from the accreditation; he perceived that the job was more into paperwork rather than the teaching itself. The situation generated a high amount of stress that caused him to resign from the job. He stated that he preferred to be a teacher whose main focus is on teaching without much paperwork.

\section{Excerpt 4}

"I just cannot, the stress was so high in high school education. The school I was teaching before they were in accreditation and they have a very high standard about it. So, It's like more paperwork than the teaching itself, so as I said but I could not do this, I wanted to be a teacher, but not a teacher that work in a lot of paperwork just to be accredited to get higher status, so I quitted, the stress was too high. It was a high-status school."

Furthermore, the participant taught ESL for the first time in his country to Korean and Chinese students. He employed the opportunities of Koreans during the winter break and gained 
experience teaching ESL students. The pay for teaching ESL was high more than enough for him
Excerpt 5
"I taught ESL online and offline to 2015. I was teaching Koreans and Chinese, that was how I started my ESL journey to foreign students. So, that was more than a year. So, I was teaching both online and one-on-one tutorial sessions to Korean students. they came to the Philippines in winter break in Korea because it was very cold in Korea. So, they went to a warm area like the Philippines. They studied as well because it's cheap in the Philippines. That was good money at that time."

\section{Preparation on Teaching Abroad}

The second deductive theme described the preparation needed to teach abroad. It also described the participant's identity and agency regarding the motivation for teaching abroad. The participant believed that the main reason to teach abroad is for prosperity. It is well known that teachers in developing countries like the Philippines are still getting underpaid. $\mathrm{He}$ believed teaching abroad would assist him in addressing this issue. Also, he mentioned other reasons such as professional development. However, it only grew after he teaches abroad. He mainly emphasizes that prosperity is the main reason why he teaches abroad.

\section{Excerpt 6}

"It is obvious, for money. That's the main reason. That's it., why would there be any reason? There are also some exposures towards English but that's the main reason. For other reasons, they are just growing while you are there. However, the main reason is that you want more money or a better life."

This theme also discovered what the participant needed to prepare before teaching abroad. He stated that he only had his teaching license, BA degree, and his pedagogical and knowledge skills as a teacher. When inquired why he did not need to have other qualifications such as a TESOL license or language proficiency test, he described that the employer did not require him to have such qualifications. He stated that he took a TESOL license and got tested on IELTS when he has already taught abroad. The participant emphasized that paper such as certification is indeed important However without the proper skills to prove the worth of a candidate's certifications, the employer would not hire that candidate.

\section{Excerpt 7}

"What I had only before teaching abroad was my teaching license and then my master, unfinished master, and my skills. That's it. I didn't have those (TESOL, IELTS, etc) when I came here. It's easy to come here, it's a when you come here it is up to you if you want to be a professional. Also, the company did not require me to have that. This is where I got my TESOL. I only had my teaching license, my skills, my passport, unfinished master's degree. We have to be skilled, the papers are just for accessory, if you all the papers needed but you are not good, they will not take you"

Furthermore, the participant elaborated on how he applied for the job he is in the moment. He described that his government facilitated its citizen to work abroad and each employer must have an MoU with the government to assure each citizen will be supervised 
properly. Thus, the government provided an official website as a job-seeking agency nationally and internationally. Then, the participant applied for the job, attended interviews, had a medical check-up, and prepared required documents. He also explained why the employer did not require TESOL or language proficiency test as the vacancy was urgent and the employer was scouting in his country.

\section{Excerpt 8}

"So, that was 2015 around February or May. In the Philippines, we have an official job-seeking website. So, if you want to look for a job abroad you just go there and look for an agency then apply. We are all under Government supervision, the employers have to have an MoU with our government. So, I applied and then I had interviews, medical checkups, some papers, The visa was paid and the flight ticket. I just prepared my government license, educational records, and medical records. I am hereby July of 2015. That was fast because it was urgent. The employer was there in Philipines scouting for English teachers there were a lot of applicants

\section{Challenges and Opportunities of Teaching Abroad}

The third deductive theme of this study focused on the challenges and opportunities the participant gained during his experience teaching abroad. The first challenge he encountered was culture shock where he engaged in different cultures and people. For example, the Kingdom of Saudi Arabia (KSA) is a strict country compared to his country, he was allowed to drink liquor in his country and it is prohibited to do so in KSA. Another example is the language where everyone does not share a similar first language to him, thus adapting and assimilating the culture was obligatory for him.

Excerpt 9

"The challenge here is, of course, the culture, and the people it is different, the language it is a lot different. I have to adapt, Philippines is an open country you can do anything you want. It is very strict here in KSA. It is like you can't even drink because it is not allowed. There is no even liquor store here as it is not allowed. If I want to drink, I have to go to another country so that is a challenge, because for me I am not a Muslim so it is a challenge."

Furthermore, He described the homesickness he often perceives. He stated that homesickness was the first he felt when he started to teach abroad. It is quite challenging to live in a new place with so much culture shock and the feeling of homesickness. The participant has been teaching for years in KSA, however, he still perceives himself as a stranger who always misses his home.

Excerpt 10

"you are being so far from your family. That is the first thing you feel, you are far from home. So you gonna miss food, gonna miss the weather, you know nothing beats home if you are in other countries. You won't feel it unless you leave your country. So, You feel you are always a stranger if you in other countries even if you stay there for a long time. You will always feel like a stranger all the time."

He tried to address the homesickness and culture shock issue by assimilating and adapting to the local customs. He realized that despite the status of English as an international language, the locals of KSA do not communicate in English. Thus, he must learn and acquire 
the local language just to communicate. He believed that learning the local language would assist him to assimilate to the local custom. He even extended his Arabic language acquisition by employing his Arabic to connect to the world of his Arabian ESL students. This strategy has helped him to be welcomed more to the society he lives in as the locals perceive an appreciation if a foreigner tries to learn their language

Excerpt 11

"I try to assimilate with their customs. Another challenge is of course the language, they say that English is a universal language, but coming here it does not matter if you speak English because many people here are trying so hard to speak English, so I have to learn their local language. Also, I teach ESL during summer break here too, for kids. I need to speak Arabic to them. I don't need to prove if I can speak Arabic, it is just that they appreciate it if I speak Arabic. Learning the students' language helps you to connect to the students' world, that is why I am learning Hindi now. I try to learn it informally."

Besides the challenges, he gained opportunities to support his motivation of teaching abroad and why he resigned from high school. He receives higher pay compared to what he received in his country. The participant currently teaches by following a certain curriculum which is repeated and saves his time in preparing the teaching material. He also said that there is no much paperwork he needs to do and the students' size is small compared to his country. These facilities and environment help him in reducing the amount of stress generated from the job.

\section{Excerpt 12}

"The benefits of being here, it is of course the money. The job is not difficult. It is easy because I don't have to make my curriculum, I don't have to prepare instructional materials, they provide everything. It is teaching here because there is not a lot of paperwork. Also, I only got a maximum of 20 students here. I don't go more than number. Back in my country, it was like 30 to 40 students in private schools, in public schools we got 60 to 80 students in one school."

\section{Teacher's Reflection}

The $4^{\text {th }}$ deductive theme is a reflection for the participant regarding his journey in teaching abroad. Firstly, he reflected on how he perceives the discussion regarding NNETs versus NETs. He believes that NETs have a unique privilege due to their passport which allows them to visit countries freely while NNETs must apply for a visa to do so. He described the privilege of the passport by reflecting on his experience finding a teaching job abroad through a job-seeking website. He stated that he discovered many employers rejected him because he does not have the passport required as employers still prefer to hire teachers from UK, New Zealand, USA, Canada, etc. 
Excerpt 13

"It is more like their privilege. They can go anywhere with their passport, so it is a privilege, not discrimination. First, they can go anywhere with their passport because they are Westerners, they got more freedom of movement. For us, we can't move without a visa, we can't go on vacation without a visa, for them to move around like to Dubai or Oman they just can move freely. We need a visa to do so. Once again, it's more like privilege, not discrimination. We know the fact that they have this powerful passport."

Excerpt 14

"I applied before, like in Teach away, Teach abroad, ESL Café, but I did not pass the qualification even if I have the experience as they prefer to lookfor the passport. That is the challenge. If your passport is USA, Canada, UK, Australia, you will have a higher chance of employment. Even if you are Asian but have those passports you can teach anywhere."

He believes such privilege is somewhat expected for him as the people who hold the passport are the native speakers of English. The participant believes that he could not care less about the privilege. He only focuses on teaching as best as he can without comparing himself to native speakers. This privilege is not perceived as discrimination for him as he believes the only discrimination that exists between him and native English speakers is a salary gap. The NETs receive a higher salary than NNETs. However, in the participant's case, they still share similar facilities without any form of discrimination.

Excerpt 15

"You will only know if you are better than native speakers through the students because they are the ones who can see if you are good or not. I can't say if I am better than them. I don't care actually, because it is their nature and their language right?. They have the power to speak the language."

Excerpt 16

"In my experience, there is no that kind of discrimination besides salary. We live in the same house, we ride the same car, we teach in the same classroom."

As this study aimed to inspire and guide its readers that EFL/ESL teachers could teach abroad, the participant reflected on what could be implemented to enhance the prosperity of EFL/ESL in-service and pre-service teachers. The participant suggested that if the government could not afford to pay the teachers properly, they should facilitate their teachers to teach abroad and let other countries pay them properly. Also, he described that to teach abroad we must globally be accepted, our certifications and degree align with our skills and competencies.

Excerpt 17

"It is like our Government wants us to stay away from the Philippines. That is happening, it is a fact that Philipinos are the most diverse in each country as workers, that is why you can find us anywhere like in Thailand and Vietnam. Remember, you must be ready and skilled. We have very limited opportunities for teachers and nurses, but we got a lot of them that is why where will we go? We go abroad." 


\section{Discussion}

This study discussed and explored the preparation, challenges and opportunities, and the participant's reflection regarding his teaching journey abroad that aims to be a reflection reading material for pre-service or in-service English teachers who aim to teach abroad. Rodriguez is a Filipino ESL teacher who has been teaching ESL for 5 years in the Kingdom of Saudi Arabia.

Firstly, the study discovered that the participant involved in this study has shown his identity and agency as a teacher as his actions and decisions described how he renegotiated with his teacher's identity. Moreover, his actions and decisions have shown that he could identify and employ what decisions and actions that need to be taken upon their self-development (Beijaard, Meijer, \& Verloop., 2004). Environment either physical or social has heavily affected his decisions and actions, through them it is possible to reflect and gain inspiration regarding teaching abroad through his identity and agency as a teacher (Pappa, Moate, Ruohotie-Lyhty, \& Eteläpelto, 2017; Ruohotie-Lyhty, 2011).

In this study, it has shown how Rodriguez addressed various new responsibilities, challenges, and expectation that were generated by his environment. It began in the earliest phase of his study; the study excavated the reason why he decided to take an English secondary education major and he believed that the major was the easiest for him to finish. This action depicts, how he was aware of his capability as a teacher and taking the major that suits him the most. It would be unwise if he picked another major (Ruohotie-Lyhty, 2018; Ruohotie-Lyhty, 2011). After he graduated, he could not apply directly as a teacher as the government has obligated teachers to have an official license by the government. He was aware of this policy and took the license exam, however, he graduated during the middle of the year which challenges him with unemployment as he could not apply for a teaching job in the middle of the year. To fill the gap, he decided to take a non-teaching job. This action reflects his selfefficacy on keeping to be productive despite the gap year, such productivity would provide a good role model for his future students (Ruohotie-Lyhty, 2018; Ruohotie-Lyhty, 2011). Furthermore, Rodriguez often renegotiated his identities through transformative development. This was described by his action and decision when he resigned as a high school teacher due to a high amount of stress and low salary, instead of switching career from teacher to a nonteaching job, he decided to teach abroad by employing an official job-seeking website and applied to a vacancy that demanded less qualification. This situation shares similar findings with the study conducted by Benson (2012) where 2 Shanghainese English teachers teach in Hong Kong, both findings reported that teachers should know what environment and expectations are suitable for the teachers. Moreover, when was inquired regarding the issue between NNETs and NETs, Rodriguez's beliefs described that he does not pay too much attention to the matter. He is aware that native English speakers have the privilege due to their mother tongue is internationally regarded as an international language. He prefers to focus on his teaching to provide optimal output for the students, as in reality colleagues and students will value work ethics and performance more than nationality (Benson, 2012).

Rodriguez also experienced self-development through opportunities he received on his journey teaching abroad. He was aware of the opportunities that were presented on his journey starting before taking his bachelor's degree until nowadays. He was challenged by various opportunities and challenges and he has developed self-efficacy and authority to adapt and take advantage, thus developing a better identity and agency as a teacher (Ruohotie-Lyhty, 2018; Ruohotie-Lyhty, 2011). When Rodriguez took his BA major, he considered which one the easiest and suitable for him, during his time abroad he has adapted to his surrounding environment and culture by avoiding habits that is not customary for the local culture and learned the local language to better connect with his students and environment. He understands 
that as an NNET he could not be as competent as NET in terms of English linguistic competence, he is aware that he can enhance his strength as NNET by learning the local language to connect to students' world and local environment (Benson, 2012). He always emphasizes that we must focus on assuring that our qualification, papers, certification reflects our skills as without it the papers would be worthless for the employers. This additive development has shown that Rodriguez has a self-sense and authority as a teacher which allows him to adapt and overcome challenges he encounters as a teacher (Brinton, 2004; Kumaravadivelu, 2003).

This study also discovered, despite the debate of NNETs vs NETs, there is no form of discrimination the participant encountered during his journey on teaching abroad, similar to previous studies reported by Ulla (2019), Farrel (2015), Songsirisak, (2015) Hickey (2014), Walkinshaw and Duong (2014), Benson (2012), Walkinshaw and Duong (2012), Ulate (2011), and Merino (1997). The only form of discrimination that exists between these studies is native English speakers always receive a higher salary than non-English speakers, the native and nonnative still share similar facilities and benefits such as housing, facilities, support, etc. Ulla (2019) reported that institutions or employers often hire NETs is due to increasing authentic exposure in learning English and aim to enhance English proficiency through the exposure. After all, the NETs, have the strength of fluency and remarkable linguistic competence which NNETs often struggle to acquire (Grubbs, Jantarach, Kettem, 2010). However, NNETs often express their gratitude for receiving their salary despite the salary gap between NNETs and NETs as they already received multiple times higher salaries than in their home countries (Ulla, 2019).

As this study aimed at non-native pre-service or in-service English teachers, this study highlighted what are the strengths of NNETs that NETs could not acquire. NNETs have the experience of success in learning English while NETs were born with it (Kirkpatrick, 2011). This allows NNETs to have intangibility and meaningful experience that could be shared among the students or developed into learning strategies (Kobayashi, 2017). To enhance their strengths, NNETs must often attend and participate in a professional development program and training opportunities they could find (Ulla, 2018; Ulla, 2017). It is challenging to transform the preference towards NETs rather than NNETs in the perspective of the employers, it is only reasonable and rationale to enhance NNETs professional identity and agency as English teachers.

\section{CONCLUSION}

This study aimed to provide guidance and inspiring read for in-service and pre-service English teachers through providing the experience of a Filipino ESL teacher who teaches abroad and covering the details of how he teaches abroad and its implication for him. Through this study, in-service and pre-service English teachers who reside in a developing country should know that they could enhance their prosperity by assuring themselves to be globally accepted English teachers and teach abroad for the sake of prosperity. Also, through teaching abroad teachers could experience various additive and transformative development that enhance their teachers' identity and agency. The authors suggested that if a teacher's home country could not afford to pay its teachers properly, they should facilitate the teachers to teach abroad and let other countries enhance their prosperity. Despite employers and institutions abroad still pay the native speakers higher than non-native speakers, yet the salary they receive is still higher than what they get in their home country. It is important to stop teachers getting underpaid as they are still a human being and requires prosperity and often underestimated of their impacts towards human civilization. Overall, teaching abroad should be considered greatly by pre-service or in-service English teachers as it offers prosperity for teachers who live in developing countries and also offer unique professional development compared to teaching in their home countries. 
This study is not without limitation, the study only explored a Filipino ESL teacher who teaches in an ESP institution. It would be more insightful if the study covered various stories of NNET ESL teachers who teach in different settings such as in public schools, private schools, and language centers, through this setting, a variety of procedures could be generated that the readers could follow regarding teaching abroad. Also, this study only discovered a story from a Filipino ESL teacher which his country already declare English as a second language and the government provides official link and agencies to assist its citizen to work abroad; it would be more insightful if future studies could explore the story of NNET teachers from different teaching institutions who come from a country that does not declare English as a second language and have no official support, especially for teachers, to work abroad. However, this study could also be developed to provide better implications for its readers through providing a training program that assures the in-service and pre-service English teachers would be globally accepted and able to teach abroad.

\section{ACKNOWLEDGEMENT}

I would like to express my gratitude to Singaperbangasa University English Education major and my research mentor who are willing to be the 2nd author Mr. Elih Sutisna Yanto of Singaperbangsa University as they had assisted me in designing, conducting, and writing this study as a part of requirements to finish my BA study. This study also did not receive any funding from any organization or individual.

\section{REFERENCES}

Amin, N. (2004). Nativism, the native speaker construct, and minority immigrant women teachers of English as a second language. In Learning and teaching from experience: Perspectives on non-native English-speaking professionals, ed. L.D. Kamhi-Stein, 6180. Ann Arbor, MI: The University of Michigan Press.Alhassan, A. (2019). EFL postgraduate students' learning needs on English-medium business programmes: An exploratory study. Language Teaching Research, 136216881985786. doi: $10.1177 / 1362168819857861$

Árva, V. \& Medgyes, P. (2000). Native and non-native teachers in the classroom. System, 28, $355-72$.

Barratt, L. \& Kontra, E. (2000). Native English-speaking teachers in cultures other than their own. TESOL Journal, 9, 19-23.

Beijaard, D., Meijer, P., \& Verloop, N. (2004). Reconsidering research on teachers'professional identity. Teaching and Teacher Education, 20(2), 107-128.

Benson, P. (2012). Learning to teach across borders: Mainland Chinese student English teachers in Hong Kong schools. Language Teaching Research, 16(4), 483-499. doi: $10.1177 / 1362168812455589$

Braun, V. and Clarke, V., 2012. Thematic analysis. APA handbook of research methods in psychology, Vol 2: Research designs: Quantitative, qualitative, neuropsychological, and biological., pp.57-71.

Clandinin, D. J., \& Connelly, F. M. (2000). Narrative inquiry: Experience and story in qualitative research. San Francisco, CA: Jossey-Bass.

Clark, E., \& Paran, A. (2007). The employability of non-native-speaker teachers of EFL: A UK survey. System, 35(4), 407-430. doi: 10.1016/j.system.2007.05.002

Creswell, J. W., Klassen, A. C., Plano Clark, V. L., \& Smith, K. C. (2011). Best practices for mixed methods research in the health sciences. Bethesda (Maryland): National Institutes of Health, 2013, 541-545.

Davies, A. 1991. The native speaker in applied linguistics. Edinburgh: Edinburgh University Press. 
Frederiksen, Crisdella Pastera. (2014). Filipino EFL Teachers Working Abroad: Some benefits and downsides for English teachers working abroad. DIVA; Malmö högskola/Lärarutbildningen.

Graddol D (2000). The Future of English? London: The English Company (UK) Ltd.

Grubbs SJ, Jantarach V, and Kettem S (2010) Studying English with Thai and native-speaking teachers. Teachers and Teaching 16(5): 559-76, doi: 10.1080/13540602.2010.507966

Hickey M (2014). English for ASEAN! African and Asian teacher migration in response to Thailand's English-language education boom. Available at: https://asian.washington.edu/events/2014-01-15/english-asean-african-andasianteacher-migration-response-thailands-english

Kachru, B.B., and C.L. Nelson. (1996). World Englishes. In Sociolinguistics and language teaching, ed. S.L. McKay and N.H. Hornberger, 71-102. Cambridge: Cambridge University Press.

Kirkpatrick A (2011) English as an Asian lingua franca and the multilingual model of ELT. Language Teaching 44(2): 212-24. doi:10.1017/S0261444810000145

Kobayashi Y (2017) ASEAN English teachers as a model for international English learners: modified teaching principles. International Journal of Applied Linguistics, 27(3): 1-15. doi.org/10.1111/ijal.12173

Kong, M. (2016). On Teaching Methods: The Personal Experiences of Teachers of English. RELC Journal, 48(2), 197-209. doi: 10.1177/0033688216661251

Kubota R, Lin A (2006) Race and TESOL: introduction to concepts and theories. TESOL Quarterly 40(3): 471-93.

Medgyes, P (1992) Native or non-native: who's worth more? ELT Journal 46(4): 340-49.

Medgyes, P. (1994). The non-native teacher. London: Macmillan.

Merino IG (1997) Native English-speaking teachers versus non-native English-speaking teachers. Revista alicantina de estudios ingleses 10: 67-79.

Moussu, L. \& Llurda, E. (2008). Non-native English-speaking English language teachers: History and research. Language Teaching, 43, 315-48.

Pappa, S., Moate, J., Ruohotie-Lyhty, M., \& Eteläpelto, A. (2017). Teachers' pedagogical and relational identity negotiation in the Finnish CLIL context. Teaching and Teacher Education, 65, 61-70.

Rampton, M.B.H. 1990. Displacing the 'native speaker': Expertise, affiliation, and inheritance. ELT Journal 44, no. 2: 97-101.

Ruohotie-Lyhty, M. (2011). Constructing practical knowledge of teaching: Eleven newly qualified language teachers' discursive agency. Language Learning Journal, 39(3), 365-380.

Ruohotie-Lyhty, M. (2018). Identity-agency in progress: Teachers authoring their identities. In Research on Teacher Identity (pp. 25-36). Springer, Cham.

Shin, S. (2008). Preparing non-native English-speaking ESL teachers. Teacher Development, 12(1), 57-65. doi: 10.1080/13664530701827749

Songsirisak P (2015). Non-native English speaker teachers: uncovering Thai EFL teachers' instructional practices in a Thai international program.http://www.vnseameo.org/TESOLConference2015/Materials/Fullpaper/Mr. \%20Prommin\%20Songsirisak.pdf

Ulla, M., 2019. Filipinos as EFL Teachers in Bangkok, Thailand: Implications for Language Education Policy in the ASEAN Region. RELC Journal, p.003368821987977.

Ulla M. (2018) English language teaching in Thailand: Filipino teachers' experiences and perspectives. Issues in Educational Research 28(4): 1080-94. http://www.iier.org.au/iier28/ulla2.pdf 
Ulla M. (2017) Teacher training in Myanmar: teachers' perceptions and implications. International Journal of Instruction 10(2): 103-18. Available at: https://eric.ed.gov/?id=EJ1138329

Ulate NV (2011) Insights towards native and non-Native ELT educators. Bellaterra Journal of Teaching \& Learning Language \& Literature 4(1): 56-79.

Walkinshaw I, Duong OTH (2014) Native- and non-native English language teachers: student perceptions in Vietnam and Japan. SAGE Open. 1-9 doi: $10.1177 / 2158244014534451$

Walkinshaw I, Duong OTH (2012) Native- and non-native speaking English teachers in Vietnam: weighing the benefits. TESL-EJ 16(3): 1-17. 